Gut, 1973, 14, 376-379

\title{
Leucocyte migration studies with spleen preparations in Crohn's disease
}

\author{
ELIZABETH R. RICHENS, K. R. GOUGH, AND M. J. WILliAMS \\ From the Royal United Hospital, Bath
}

SUMMARY Thirty-nine patients with Crohn's disease and 17 normal people were tested for hypersensitivity to sarcoid and normal spleen suspensions using the leucocyte migration test. In $26 \%$ of the Crohn's cases migration was inhibited, whereas inhibition was not significant in the control group. Migration inhibition did not appear to be related to duration or activity of the disease. Sixty-two percent of the Crohn's patients showed migration stimulation against normal spleen, a phenomenon that did not occur in the control group.

The aetiology of Crohn's disease remains unknown, but the characteristic histological lesion bears a strong resemblance to that seen in sarcoidosis (Blackburn, Hadfield, and Hunt, 1939). Both diseases feature granulomata with multinucleate giant cells and epithelioid cells surrounded by aggregates of mononuclear cells, and both share several immunological reactions (Jones, 1967; Jones, Housley, Ashurst, and Hawkins, 1969; Williams, 1965; Binder, Spiro, and Thayer, 1966; Brown, Taub, Present, and Janowitz, 1970; Walker and Greaves, 1969).

The Kveim antigen has been considered a specific diagnostic skin test in sarcoidosis, and, because of the similarities between sarcoidosis and Crohn's disease, this antigen has been tested in patients with Crohn's disease. Used as a skin test, both positive and negative responses have been found and it has been suggested that different batches of sarcoid spleen are responsible for the variable responses (Williams, 1965; Mitchell, Cannon, Dyer, Hinson, and Willoughby, 1969; Hurley and Lane, 1971).

Recently the leucocyte migration test has been used to test for hypersensitivity to Kveim antigen in patients with Crohn's disease, a similar proportion of positive results being obtained in both studies (Willoughby and Mitchell, 1971; Brostoff and Walker, 1971). There appeared to be no correlation of positive results with activity of the disease, although in one study leucocytes from patients receiving corticosteroid treatment showed less inhibition of migration than those from patients not on such treatment.

Received for publication 21 February 1973.

\section{Patients}

Thirty-nine patients with Crohn's disease were tested. Their mean age was 35 years (17-70 years). Of these, 28 had positive histological proof of Crohn's disease and the remaining 11 had positive clinical and radiological evidence of the disease. Twenty-two patients were judged to be in an active phase of the disease on clinical criteria such as diarrhoea, weight loss, pain, and fever, whereas in 17 cases the condition appeared quiescent. The majority, 26, had not had immunosuppressive treatment with corticosteroids or azathioprine. Four patients were studied both before and after immunosuppressive treatment. The length of history varied from recent diagnosis to 20 years. Twenty-two patients had undergone intestinal surgery for the disease.

A group of 17 normal subjects proportionately matched as far as possible for age and sex with the Crohn's group was also tested. The mean age was 37 years (18-71 years).

\section{LEUCOCYTE MIGRATION TEST}

The method used was that of Soborg and Bendixen (1969). Leucocytes harvested from heparinized venous blood were allowed to migrate from capillary tubes into chambers containing $20 \%$ foetal calf serum in Eagle's medium MEM. After 21 hours' incubation at $37^{\circ} \mathrm{C}$ the areas of migration were measured, and a migration index was calculated by dividing the mean of the measurements in the chambers containing antigen by the mean of a similar number of measurements from the control chambers. 
All measurements were carried out in quadruplicate. A migration index of less than $\mathbf{0 . 8}$ indicates significant inhibition of migration and an index of greater than 1.2 significant stimulation.

\section{ANTIGENS}

A type 3 Chase-Siltzbach sarcoid spleen suspension K19 was used and compared with two normal spleen suspensions, type $1 \mathrm{NS} 3$ and type $3 \mathrm{NS} 2$, provided by the Central Public Health Laboratory, London, NW9. An antigen concentration of 0.025 by volume of the final culture medium was used in all experiments. This was intermediate between the concentrations used by Willoughby and Mitchell of 0.04 and by Brostoff and Walker of 0.005 .

\section{Results}

Seventeen control subjects were tested with sarcoid spleen K19 and normal spleen NS3 (fig 1). The mean migration indices $( \pm$ SD) obtained were 0.91 \pm 0.10 and $0.95 \pm 0.10$ respectively.

A group of 25 Crohn's patients was then tested (fig 2) against the same two antigens, one patient being tested twice. The mean migration indices were $0.93 \pm 0.14$ and $1.30 \pm 0.24$ respectively. Against the sarcoid spleen four patients $(16 \%)$ showed migration inhibition with indices of $<0.8$ and against the normal spleen suspension $17(65 \%)$ showed migration stimulation with indices of $>1 \cdot 20$.

The results obtained with the sarcoid spleen show no significant difference between the control population and the Crohn's patients, but with the normal spleen the two groups were significantly different $(\mathbf{P}<0.001)$.

The migration indices obtained with both spleen suspensions were found to be unaffected by such factors as the state of activity of the disease, whether or not the patient had undergone surgery, or the duration of the disease. However, the group of patients on immunosuppressive therapy showed significantly less stimulation against normal spleen $(0.02>P>0.01)$ than those not on such treatment. The mean migration indices for these groups were $1 \cdot 14 \pm 0.14$ and $1.36 \pm 0 \cdot 24$ respectively.

At this stage in the work it became necessary to reblend the sarcoid spleen material which, being highly hygroscopic, had come out of solution. A second group of 14 Crohn's patients was then tested again the reblended sarcoid spleen $\mathrm{K} 19$ and the normal spleen NS3, one patient again being tested twice (fig 3). The mean migration index against the sarcoid spleen was $0.87 \pm 0.02$ and against the normal spleen $1 \cdot 15 \pm 0 \cdot 15$. Forty percent of the patients in this group now showed migration

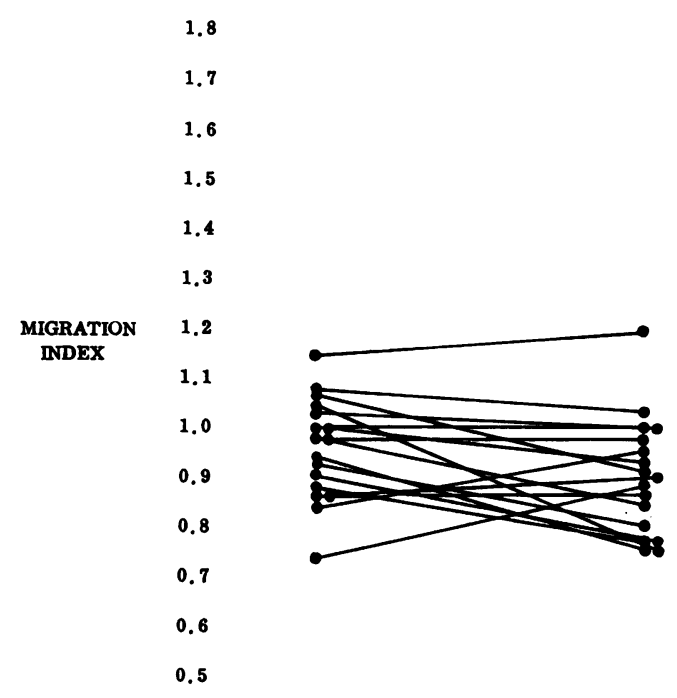

$\mathbf{A}$

$\mathbf{B}$

Fig 1 Leucocyte migration test in control subjects with (A) normal spleen (NS3) and (B) sarcoid spleen (K19).

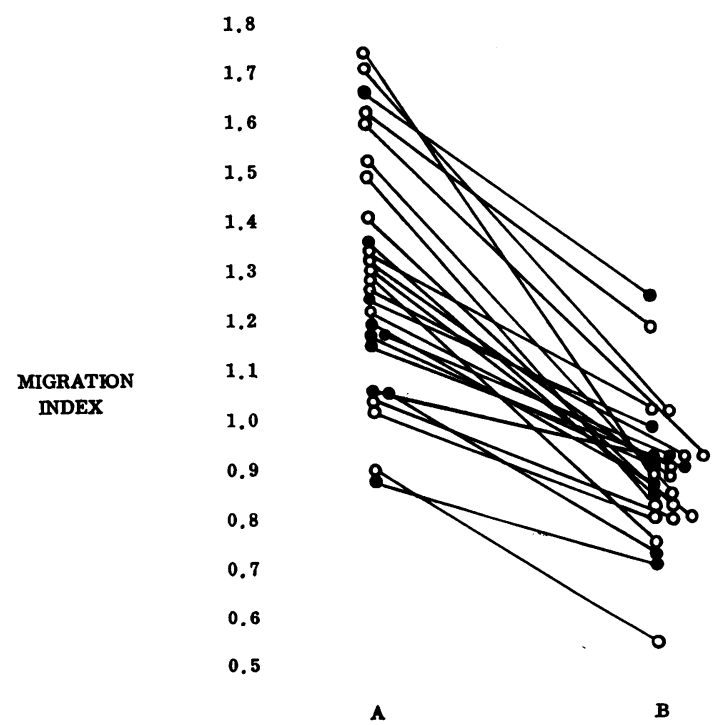

Fig 2 Leucocyte migration test in Crohn's patients with (A) normal spleen (NS3) and (B) sarcoid spleen (L19). - With immunosuppressive drugs; $\bigcirc$ without immunosuppressive drugs. 


\begin{tabular}{|c|c|c|c|c|c|c|}
\hline \multirow[t]{2}{*}{ Case } & \multicolumn{3}{|c|}{ Immunosuppressive Treatment } & \multicolumn{3}{|c|}{ Migration Index with Spleen Preparations (1:40) } \\
\hline & Days & Drugs & Benefit & Sarcoid K19 & Normal NS3 & Normal NS2 \\
\hline A.A. & $\begin{array}{r}0 \\
20\end{array}$ & $\overline{\text { Azathioprine; prednisone }}$ & $\overline{\text { None }}$ & $\begin{array}{l}0.58 \\
0.93\end{array}$ & $\begin{array}{l}0 \cdot 89 \\
1 \cdot 16\end{array}$ & \multirow{2}{*}{$\begin{array}{l}\text { Not } \\
\text { performed }\end{array}$} \\
\hline D.H. & $\begin{array}{r}0 \\
40\end{array}$ & $\begin{array}{l}\text { Prednisone } \\
\text { Azathioprine; prednisone }\end{array}$ & $\overline{\text { Good }}$ & $\begin{array}{l}1.27 \\
0.76\end{array}$ & $\begin{array}{l}1.63 \\
0.65\end{array}$ & \\
\hline M.H. & $\begin{array}{r}0 \\
27\end{array}$ & $\overline{\text { Azathioprine; prednisone }}$ & $\overline{\text { Good }}$ & $\begin{array}{l}1 \cdot 21 \\
0.87\end{array}$ & $\begin{array}{l}1 \cdot 75 \\
1 \cdot 27\end{array}$ & 0.87 \\
\hline M.C. & $\begin{array}{r}0 \\
10\end{array}$ & $\overline{\text { Azathioprine; prednisone }}$ & $\overline{\text { Good }}$ & $\begin{array}{l}0.82 \\
1.07\end{array}$ & $\begin{array}{l}1.40 \\
1.01\end{array}$ & $\begin{array}{l}1.00 \\
1.08\end{array}$ \\
\hline
\end{tabular}

Table Mean migration index in four patients before and after immunosuppressive treatment using sarcoid and normal spleen preparations

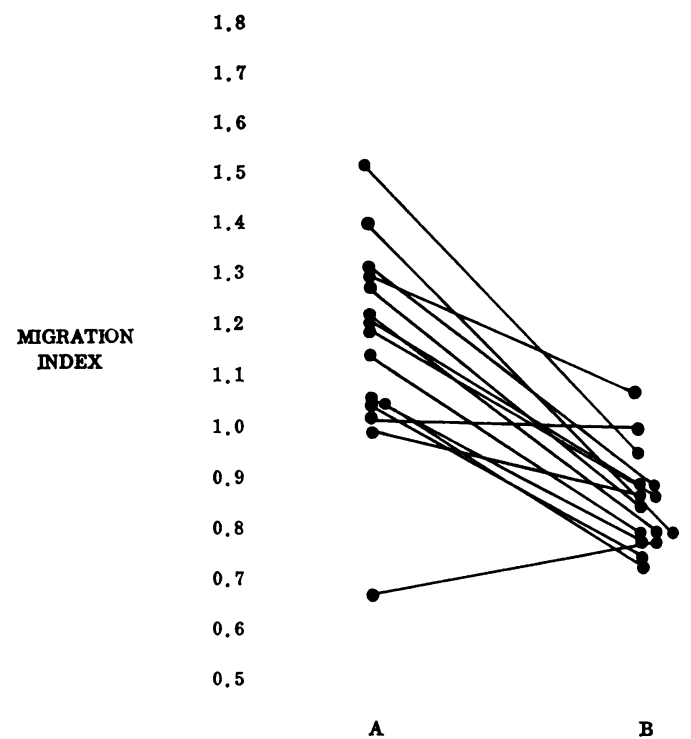

Fig 3 Leucocyte migration test in Crohn's patients with (A) normal spleen (NS 3) and (B) sarcoid spleen (resuspended $)(K 19)$.

indices of 0.8 with the sarcoid spleen and $50 \%$ showed migration indices of 1.2 with the normal spleen suspension. Only two patients showed both of these effects together; neither was on immunosuppressive therapy.

In four untreated patients with an abnormal response to either the sarcoid (three patients) or normal spleen (three patients) or to both preparations (one patient) it was possible to obtain further migration indices from 10 to 40 days after the start of immunosuppressive treatment (see table). In three cases, a marked clinical improvement was noted and a coincident return to a normal migration index range was seen in two of these. In two of these patients the effect of a third antigen, type 3 NS2, a normal spleen suspension, was also examined. It was found to give a migration index in the normal range, ie, between 0.8 and $1 \cdot 2$.

\section{Discussion}

The leucocyte migration test is considered to be an indicator in vitro of cellular hypersensitivity and correlates well with other parameters such as skin tests with a delayed time course. The results obtained in this work confirm that in a proportion of Crohn's patients there appears to be a state of cellular hypersensitivity to the sarcoid spleen antigen. Using the reblended sarcoid material, $50 \%$ of the patients tested showed inhibition, a similar proportion to that found by Willoughby and Mitchell (1971), and by Brostoff and Walker (1971). The reasons why only a proportion of the cases show these positive results remain obscure. We could show no significant correlation between leucocyte inhibition and activity of the disease, length of history, or previous surgery.

Using the normal spleen (type $1 \mathrm{NS} 3$ ), $64 \%$ of our patients showed migration stimulation, and when the group on immunosuppressive therapy are excluded this figure rises to $74 \%$. Abnormal migration indices, ie, low or high values, tended to be abolished when the patient was treated with immunosuppressive drugs. Willoughby made similar observations (1971).

The fact that migration stimulation was seen with only one of the normal spleens suggests that this preparation is not completely bland. The preparation used was from a new spleen (type 1 NS3) but similar effects have been noted, although not to such a marked degree, with other normal spleen suspensions (Willoughby, personal communication). It is also known that some normal spleens will produce granulomata on skin testing, similar to those seen in sarcoidosis with the Kveim test. However, the effect observed with the type 1 NS3 spleen was confined to the Crohn's patients and presumably reflects a sensitization of these patients to an antigen present 
in the preparation. Lymphocyte sensitization to a range of antigens has been shown in Crohn's and sarcoidosis cases and it has been suggested that either 'normal' people may have a latent sarcoid pathological process, or that cellular sensitization to multiple antigens is not fundamental to either disease (Caspary and Field, 1971).

Further evidence is now also forthcoming of sensitization to sarcoid spleen suspension in conditions where epithelioid granulomata are not a feature, for example, coeliac disease and dermatitis herpetiformis (Pagaltsos, Kumar, Willoughby, and Dawson, 1971). However, our work would seem to support the suggestion of an immunological link between sarcoidosis and Crohn's disease. Further investigation, using other immunological techniques, seems indicated.

We thank Dr D. N. Mitchell and Dr J. M. T. Willoughby for their advice and for arranging the supply of the spleen suspensions made available by Mrs M. Di Ghero, Standards Laboratory for Serological Reagents, Central Public Health Laboratory, Colindale, London, NW9.

\section{References}

Bendixen, G., and Soborg, M. (1969). A leucocyte migration technique for in vitro detection of cellular (delayed type) hypersensitivity in man. Dan. med. Bull., 16, 1-6.

Binder, H. J., Spiro, H. M., and Thayer, W. R., Jr. (1966). Delayed hypersensitivity in regional enteritis and ulcerative colitis. Amer J. Dis., 11, 572-574.

Blackburn, G., Hadfield, G., and Hunt, A. H. (1939). Regional ileitis. St Barts. Hosp. Rep., 72, 181-224.

Brostoff, J., and Walker, J. G. (1971). Leucocyte migration inhibition with Kveim antigen in Crohn's disease. Clin. exp. Immunol., 9, 707-711.

Brown, S. M., Taub, R. N., Present, D. H., and Janowitz, H. D. (1970). Short-term lymphocyte cultures in regional enteritis. Lancet, $1,1112$.

Caspary, E. A., and Field, E. J. (1971). Lymphocyte sensitization. Brit. med. J., 3, 369-370.

Hurley, T. H., and Lane, W. R. (1971). The Kveim controversy. Lancet, $2,1373$.

Jones, J. V. (1967). Development of hypersensitivity to dinitrochlorobenzene in patients with sarcoidosis. Clin. exp. Immunol., 2 , 477-487.

Jones, J. V., Housley, J., Ashurst, P. M., and Hawkins, C. F. (1969). Development of delayed hypersensitivity to dinitrochlorobenzene in patients with Crohn's disease. Gut, 10, 52-66.

Mitchell, D. N., Cannon, P., Dyer, N. H., Hinson, K. F. W., and Willoughby, J. M. T. (1969). The Kveim test in Crohn's disease. Lancet, 2, 571-573.

Pagaltsos, A. S., Kumar, P. J., Willoughby, J. M. T., and Dawson, A. M. (1971). In-vitro inhibition of leucocyte migration by sarcoid spleen suspension in coeliac disease and dermatitis herpetiformis. Lancet, 2, 1179-1180.

Walker, J. G., and Greaves, M. F. (1969). Delayed hypersensitivity and lymphocyte transformation in Crohn's disease and proctocolitis. Gut, 10, 414.

Williams, W. J. (1965). A study of Crohn's syndrome using tissue extracts in the Kveim and Mantoux tests. Gut, 6, 503-505.

Willoughby, J. M. T., and Mitchell, D. N. (1971). In-vitro inhibition of leucocyte migration in Crohn's disease by a sarcoid spleen suspension. Brit. med. J., 2, 155-157. 